\title{
Immobilization of Fluorine in Reduced Slag by Addition of Crystalline Hydroxyapatite and Glassy Calcium Phosphate Using a Calcining Process
}

\author{
Akira Saitoh $^{1, *}$, Hirokazu Goto ${ }^{2}$, Yoshihisa Tamada ${ }^{1}$, Yuki Ogawa ${ }^{1}$ and Hiromichi Takebe ${ }^{1}$ \\ ${ }^{1}$ Graduate School of Science and Engineering, Ehime University, Matsuyama 790-8577, Japan \\ ${ }^{2}$ Technology Management section, Yamato Kogyo Co., Ltd., Himeji 671-1192, Japan
}

\begin{abstract}
The ability of a variety of hydroxyapatite (HAp) sources, including animal bone and calcium phosphate glasses, is demonstrated to immobilize fluorine in slag through calcining processes. The slowly cooled slags were calcined in a furnace along with hydroxyapatite, animal bone, and calcium meta-phosphate glasses. As a result, fluoro-hydroxyapatite was formed, confining the fluorine ions in the formed crystal, leading to the suppression of the dissolution of fluorine ion. Each of the samples demonstrated a low elution of fluorine ions (less than 0.8 ppm), measured by leaching method. The quantity evaluation of formed apatite-like crystal and other subsidiaries were conducted for the treatments by adding recycled animals' bones as the source of calcium phosphate, as well as reagent HAp and meta calcium phosphate glasses. [doi:10.2320/matertrans.MT-M2020098]
\end{abstract}

(Received March 23, 2020; Accepted May 28, 2020; Published July 3, 2020)

Keywords: slag, fluorine, hydroxyapatite, calcium phosphate crystal, phosphate glass, calcination process

\section{Introduction}

The slag produced as a byproduct of iron smelting contains a high concentration of iron and thus requires further processing to recover this iron. Several treatments have been practiced in many steel refining works. ${ }^{1-3)}$ Among the several processing treatments that have been used to depolymerize and reduce the viscosity of the high-viscous slag consisting of $\mathrm{SiO}_{2}$ - and $\mathrm{Al}_{2} \mathrm{O}_{3}$-based melts, ${ }^{1,2)}$ one involves the use of $\mathrm{CaF}_{2}$ to reduce the liquidus temperature and reduce the sulfur concentration of the slag. ${ }^{3)}$ However, this process has a low recyclability for source of cement use, as fluorine can elute into the underground water via soil during this process. The concentration of fluorine must be less than $3 \mathrm{wt} . \%$ in slag ${ }^{4)}$ and less than $0.8 \mathrm{ppm}$ in the eluted water by dissolution test. ${ }^{5)}$ Confining mobile fluorine ions $\left(\mathrm{F}^{-}\right)$into a stable crystalline may prevent their dissolution into water and allow for improved recyclability as secondary materials.

Fluoro-hydroxyapatite (FAp, $\left.\mathrm{Ca}_{10}\left(\mathrm{PO}_{4}\right)_{6} \mathrm{~F}_{2}\right)$, which contains alternating layers of $\mathrm{CaO}$ and fluorine, and isolated $\mathrm{PO}_{4}$ tetrahedral units with six-membered rings, ${ }^{6)}$ is a stable crystal. It is an advantage that the reduced slag possesses abundant $\mathrm{CaO}$. Therefore, if $\mathrm{P}_{2} \mathrm{O}_{5}$ content is additionally provided, the FAp can be formed by confining fluorine from isolated $\mathrm{CaF}_{2}$. As reduced slag does not contain phosphorous pentoxide $\left(\mathrm{P}_{2} \mathrm{O}_{5}\right)$, it must be added to the slag for hydroxyapatite $\left(\mathrm{HAp}, \mathrm{Ca}_{10}\left(\mathrm{PO}_{4}\right)_{6}(\mathrm{OH})_{2}\right)$ to be created.

As the global population continues to increase, food shortages can be expected. ${ }^{7)}$ Chemically synthesized fertilizers are commonly utilized in grain agriculture and often require phosphorus. Animal bones contain an abundant calcium phosphate matrix and HAp, which partially provides alternation of $\mathrm{P}_{2} \mathrm{O}_{5}$ content. ${ }^{7}$ )

This work therefore aims to move elemental fluorine from $\mathrm{CaF}_{2}$ into crystalline FAp obtained by isothermal heating of the reagent $\mathrm{HAp}$ with pig bones and a meta $\mathrm{CaO}-\mathrm{P}_{2} \mathrm{O}_{5}$ glass.

*Corresponding author, E-mail: asaito@ehime-u.ac.jp

\section{Experimental Procedure}

The reagent-grade monoclinic $\mathrm{Ca}_{10}\left(\mathrm{PO}_{4}\right)_{6}(\mathrm{OH})_{2}$ crystal (99.99\%, KISHIDA CHEMICAL Co., Ltd.), pig bones, and $50 \mathrm{CaO}-50 \mathrm{P}_{2} \mathrm{O}_{5}$ glasses in molar percent, which were respectively mixed with conventional reduced slag with 50 60 wt. \% of $\mathrm{CaO}, 10-20$ wt.\% of $\mathrm{SiO}_{2}, \sim 30$ wt.\% of $\mathrm{Al}_{2} \mathrm{O}_{3}$ (see Fig. 1), and rest of $\mathrm{CaF}_{2}$ with more than $1.5 \mathrm{wt} \%$, were pulverized into powders of particle size $\leq 35 \mu \mathrm{m}$ in diameter using an agate mortar and pestle and then independently isothermally heated. For the purpose of investigating the mixing effect of $\mathrm{P}_{2} \mathrm{O}_{5}$ source, we made a sample with a ratio of $\mathrm{P}_{2} \mathrm{O}_{5}$ source/slag in wt. \% from 0.4 to 2.0 with an insertion step of $0.2-0.6$, depending on a kind of $\mathrm{P}_{2} \mathrm{O}_{5}$ source.

Each powder (mixed) sample of approximately $5 \mathrm{~g}$ were put in alumina crucibles and heated in an electrical furnace for $1 \mathrm{~h}$ at $1450^{\circ} \mathrm{C}$. The samples were then cooled to room temperature for $8 \mathrm{~h}$ in air in the furnace. X-ray diffraction

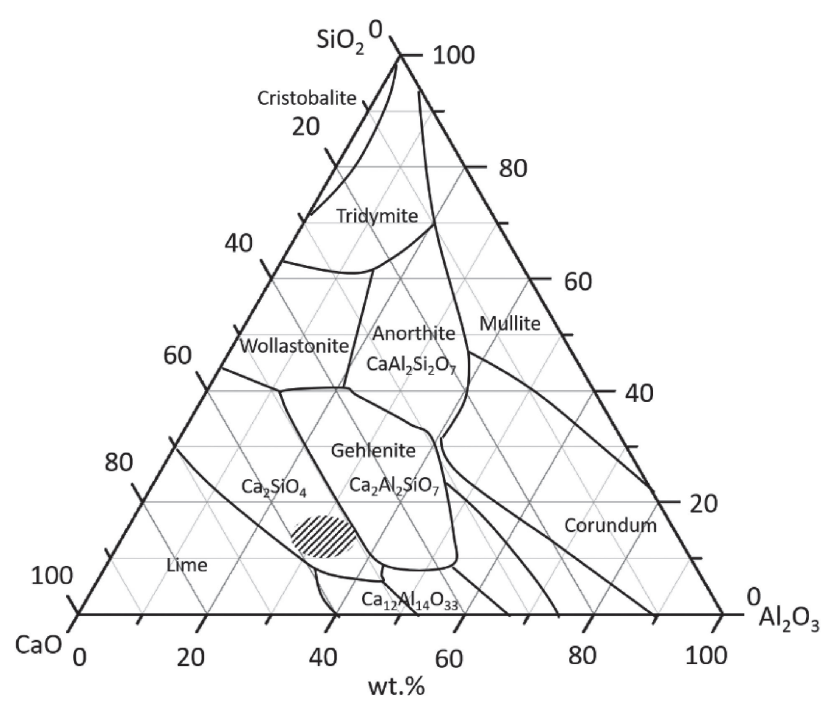

Fig. 1 Ternary phase diagram of the $\mathrm{CaO}-\mathrm{Al}_{2} \mathrm{O}_{3}-\mathrm{SiO}_{2}$ system, including the studied reduced slag. ${ }^{9)}$ 
(XRD) spectra were taken of the pulverized samples (1$10 \mathrm{mg}$ in weight) at $45 \mathrm{keV}$ and with a $40 \mathrm{~mA}$ tube. The results were analyzed using the Rietveld simulation ${ }^{8)}$ to quantitatively identify the molar fractions of the $\mathrm{Ca}_{2} \mathrm{Al}_{2} \mathrm{O}_{7}$, $\mathrm{Ca}_{10}\left(\mathrm{PO}_{4}\right)_{6} \mathrm{~F}_{2}, \mathrm{Ca}_{3}\left(\mathrm{PO}_{4}\right)_{2}, \mathrm{Ca}_{12} \mathrm{Al}_{14} \mathrm{O}_{33}$, and $\mathrm{CaF}_{2}$ crystals in the calcined samples.

The leaching test was demonstrated using the samples with sizes of $2 \mathrm{~mm}$ and weighed $20 \mathrm{~g}$. The sample was immersed in $200 \mathrm{~mL}$ of ultra-pure water solution contained in a plastic bottle. The solution with calcined slag was shaken with a swing width of $45 \mathrm{~mm}$ and at a rotating speed of $200 \mathrm{rpm}$ for $6 \mathrm{~h}$. Then, the remaining solution was filtrated by a membrane filter with a pore diameter of $0.45 \mu \mathrm{m}$.

The filtrated liquid sample was adequately diluted to $5-400$ times concentrations by adding $3 \% \mathrm{HNO}_{3}$ aqueous solution. The amounts of $\mathrm{F}^{-}$ions in the elution liquid were evaluated at least three times for each sample, which were recorded by ion chromatograph method.

\section{Results and Discussions}

A ternary phase diagram of the $\mathrm{CaO}-\mathrm{Al}_{2} \mathrm{O}_{3}-\mathrm{SiO}_{2}$ system is shown in Fig. 1, ${ }^{7)}$ where the studied reduced slag contains, in wt. $\%, 50-60 \% \mathrm{CaO}, 10-20 \% \mathrm{SiO}_{2}$, and $\sim 30 \% \mathrm{Al}_{2} \mathrm{O}_{3}$ is highlighted by the hatched ellipsoidal area. Thus, although the composition of the slag resembles cement, which is a possible use for a recycled slag, the large amount of $\mathrm{CaO}$ enables to use roadbed material after treatment of confinement of fluorine.

The resulting XRD patterns from the heat-treated powdered slag at HAp-to-slag weight ratios of $0.4,1.0$, 1.5, and 2.0 are shown in Figs. 2(a)-(d), respectively. The gehlenite $\left(\mathrm{Ca}_{2} \mathrm{Al}_{2} \mathrm{O}_{7}\right), \mathrm{C} 12 \mathrm{~A} 7\left(\mathrm{Ca}_{12} \mathrm{Al}_{14} \mathrm{O}_{33}\right)$, and FAp $\left(\mathrm{Ca}_{10}\left(\mathrm{PO}_{4}\right)_{6} \mathrm{~F}_{2}\right)$ phases were observed in the samples.

The XRD patterns from the heat-treated powdered slag at bone-to-slag weight ratios of $0.4,1.0,1.5$, and 2.0 are shown in Figs. 3(a)-(d), respectively. The gehlenite $\left(\mathrm{Ca}_{2} \mathrm{Al}_{2} \mathrm{O}_{7}\right)$, C12A7 $\left(\mathrm{Ca}_{12} \mathrm{Al}_{14} \mathrm{O}_{33}\right)$, and FAp $\left(\mathrm{Ca}_{10}\left(\mathrm{PO}_{4}\right)_{6} \mathrm{~F}_{2}\right)$ phases were observed in the samples. We here note that it is impossible to exclude the process during that $\mathrm{OH}$ in the reagent of $\mathrm{HAp}$ $\left(\mathrm{Ca}_{10}\left(\mathrm{PO}_{4}\right)_{6}(\mathrm{OH})_{2}\right)$ or unexpected and feasible $\mathrm{H}_{2} \mathrm{O}$ molecule in phosphate glass might react fluorine in $\mathrm{CaF}_{2}$, leading to a formation of $\mathrm{HF}$ gas, at high temperature.

The XRD patterns from the heat-treated powdered slag containing a meta $\mathrm{CaO}-\mathrm{P}_{2} \mathrm{O}_{5}$ glass-to-slag weight ratio of 0.4, 1.0, and 2.0 are shown in Figs. 4(a)-4(c), respectively. The gehlenite $\left(\mathrm{Ca}_{2} \mathrm{Al}_{2} \mathrm{O}_{7}\right)$, C12A7 $\left(\mathrm{Ca}_{12} \mathrm{Al}_{14} \mathrm{O}_{33}\right)$, FAp $\left(\mathrm{Ca}_{10}\left(\mathrm{PO}_{4}\right)_{6} \mathrm{~F}_{2}\right)$, TCP $\left(\mathrm{Ca}_{3}\left(\mathrm{PO}_{4}\right)_{2}\right)$ phases were observed in the samples.

The ion chromatographs of the calcined samples obtained from the dissolution of the mixed HAp and reduced slag at HAp-to-slag weight ratios of 0.8 and 1.5 are shown in Figs. 5(a) and 5(b), respectively, where each peak represents anions in the ultra-pure water solution. The first peak, located near a retention time of $4 \mathrm{~min}$, is due to the presence of $\mathrm{F}^{-}$ ions. The concentration of dissolved $\mathrm{F}^{-}$ions in both cases was less than $0.8 \mathrm{ppm}$, which is within the threshold set by the regulation, ${ }^{10)}$ as is shown in Fig. 5(b). Also, in Fig. 6(a) and (b) the chromatographs of the samples for the pig bone and slag are presented. Here, approximately two times of
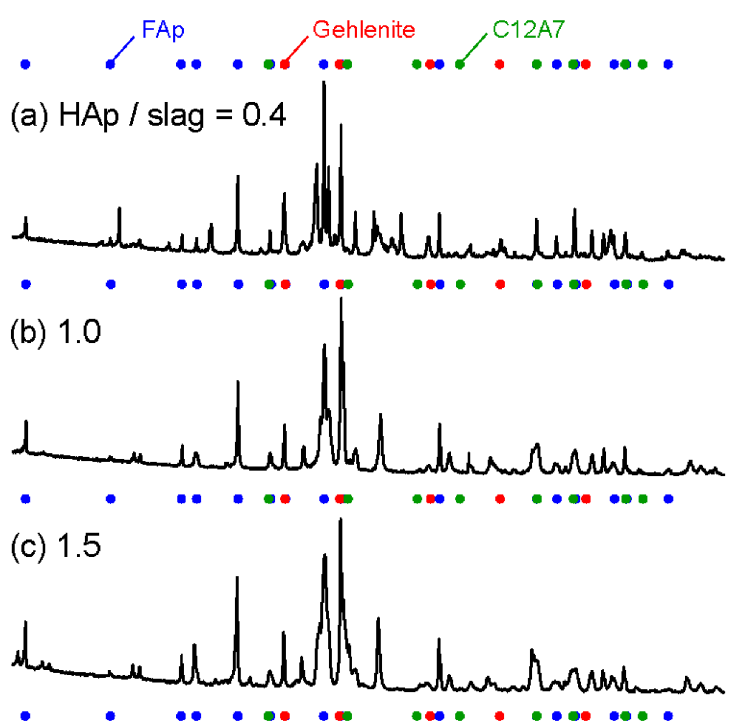

(d) 2.0

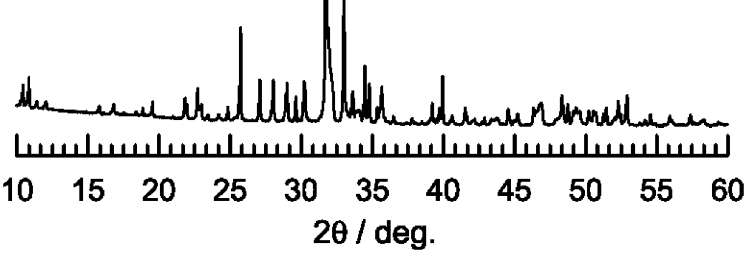

Fig. 2 Powder XRD patterns of the heat-treated slag at hydroxyapatite (HAp)-to-slag weight ratios of (a) 0.4, (b) 1.0, (c) 1.5, and (d) 2.0.

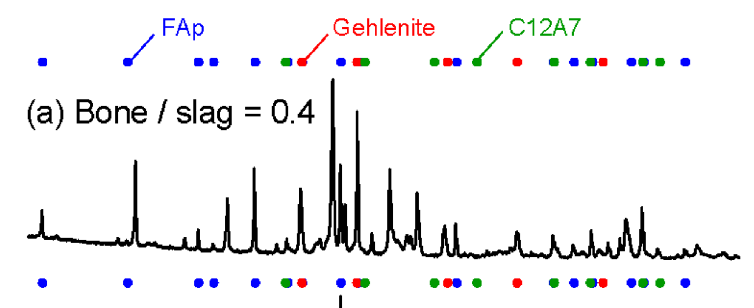

(b) 1.0
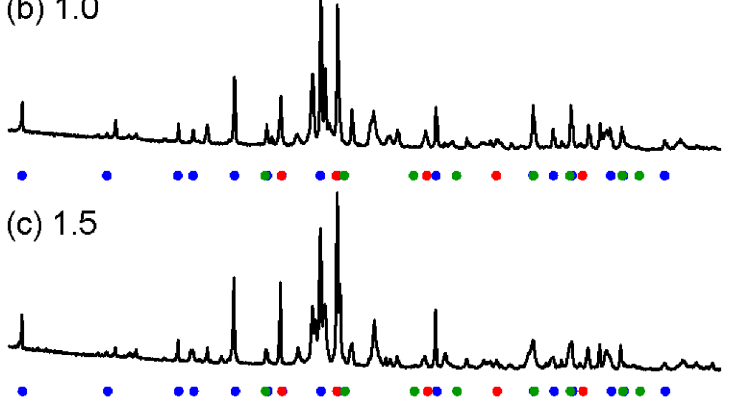

(d) 2.0

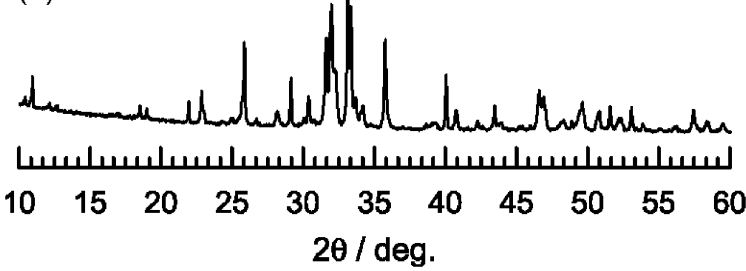

Fig. 3 Powder X-ray diffraction (XRD) patterns of the heat-treated slag at bone-to-slag weight ratios of (a) 0.4 , (b) 1.0, (c) 1.5, and (d) 2.0.

amount of bone was necessary because the bones contained approximately $50 \mathrm{wt}_{0} \% \mathrm{HAp}^{7)}$ As a result, more bone was necessary to form a similar amount of FAp (see Fig. 8(a)). 


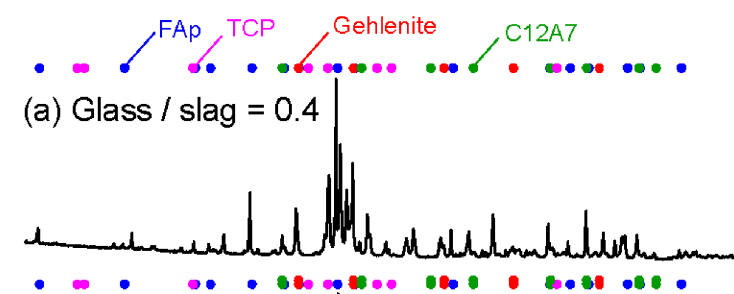

(b) 1.0
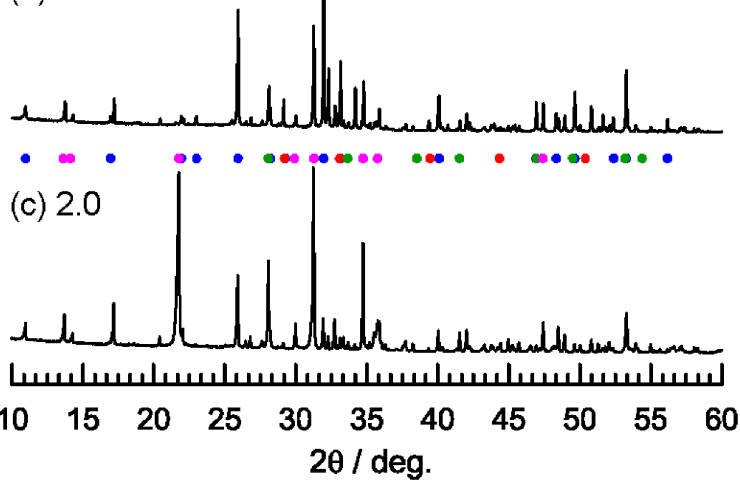

Fig. 4 Powder XRD patterns of the heat-treated slag at meta $\mathrm{CaO}-\mathrm{P}_{2} \mathrm{O}_{5}$ glass-to-slag weight ratios of (a) 0.4, (b) 1.0, and (c) 2.0, where TCP means tricalcium phosphate, $\mathrm{Ca}_{3}\left(\mathrm{PO}_{4}\right)_{2}$.

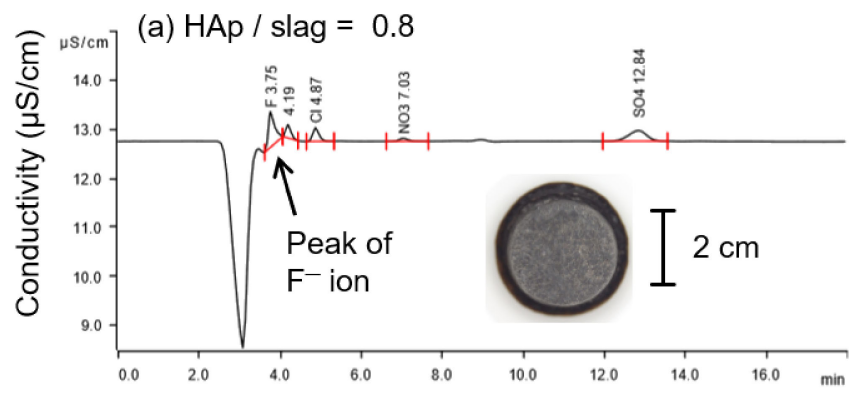

(b) HAp / slag $=1.5$

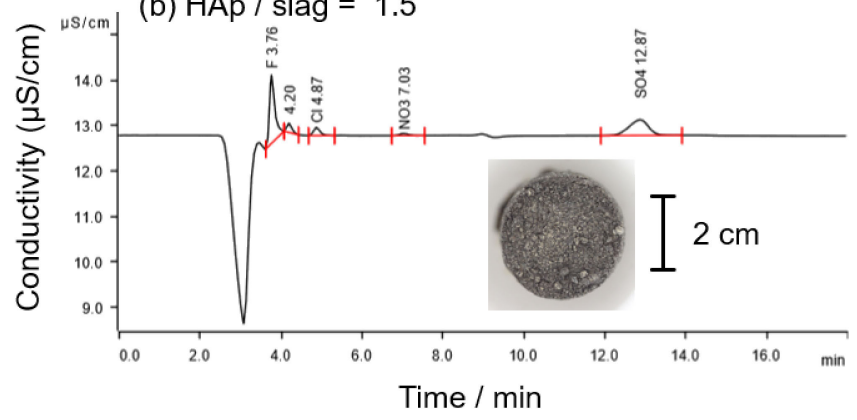

Fig. 5 Chromatographs obtained from the dissolution of the reduced calcined slag with an HAp-to-slag weight ratios of (a) 0.8 and (b) 1.5 in ultra-pure water, where the inset photos show the calcined slag before dissolution.

The effect of immobilization of $\mathrm{F}^{-}$are elucidated in the samples of the mixed meta $50 \mathrm{CaO}-50 \mathrm{P}_{2} \mathrm{O}_{5}$ glass and reduced slag at weight ratios of 1.0 and 2.0 are shown in Figs. 7(a) and (b), respectively.

The correlation between the $\mathrm{P}_{2} \mathrm{O}_{5}$, which means net weight of HAp, bone, and intriguingly $\mathrm{P}_{2} \mathrm{O}_{5}$ in $50 \mathrm{CaO}-50 \mathrm{P}_{2} \mathrm{O}_{5}$ glass (taken from $4 \mathrm{~g}$ to $20 \mathrm{~g}$ ), to slag weigh ratio and resulting fraction of FAp and C12A7 after calcination (before elution) and the concentration of eluted $\mathrm{F}^{-}$are shown in Figs. 8(a)

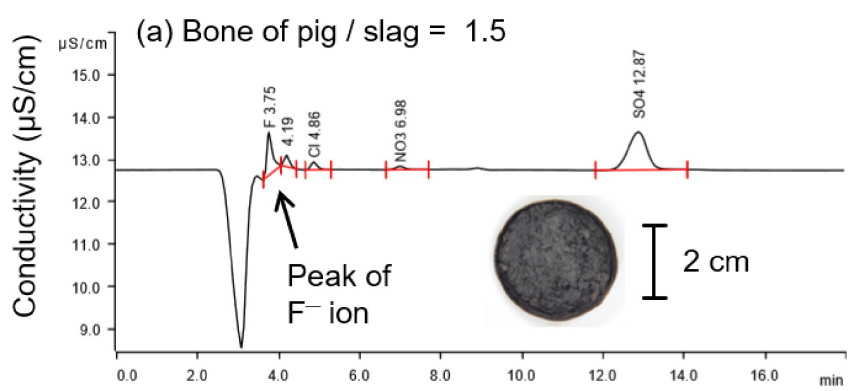

(b) Bone of pig / slag $=2.0$

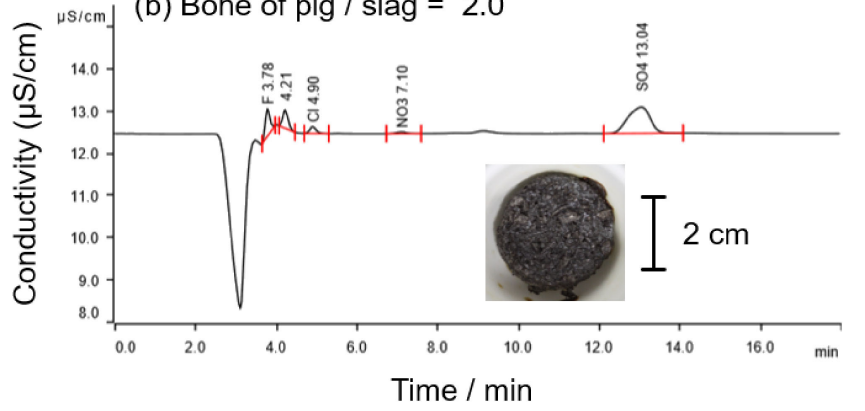

Fig. 6 Chromatographs obtained from the dissolution of the reduced calcined slag with a bone-to-slag ratios of (a) 1.5 and (b) 2.0 in ultra-pure water, where the inset photos show the calcined slag before dissolution.
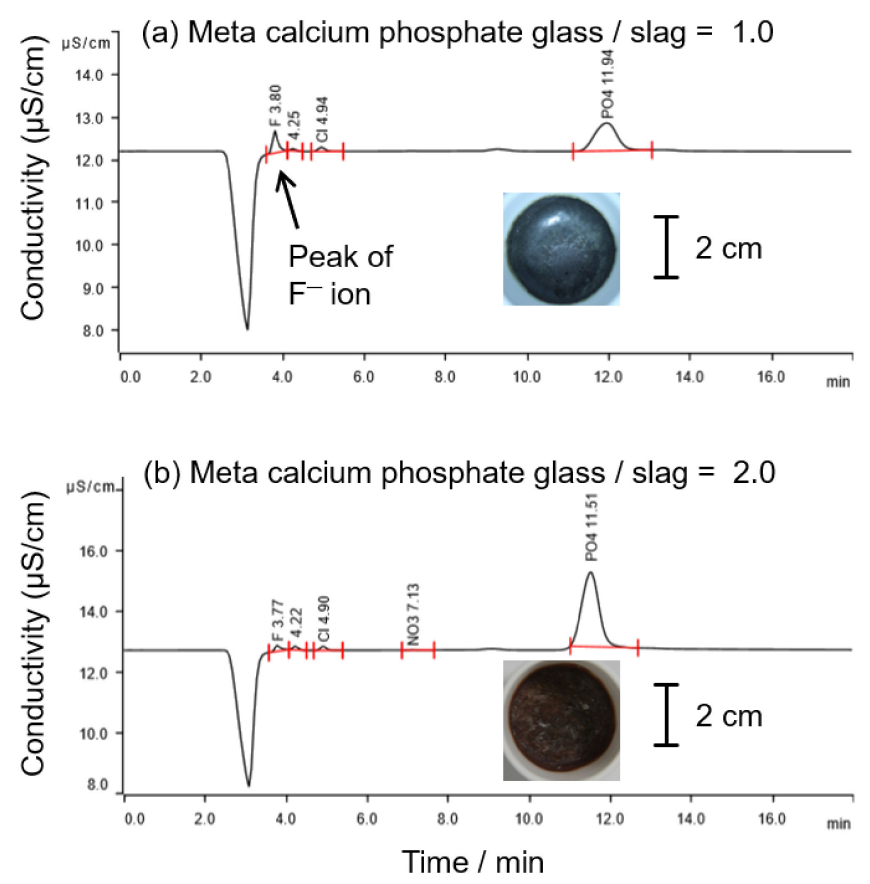

Fig. 7 Chromatographs obtained from the dissolution of the reduced calcined slag with meta $\mathrm{CaO}-\mathrm{P}_{2} \mathrm{O}_{5}$ glass-to-slag weight ratios of (a) 1.0 and (b) 2.0 in ultra-pure water, where the inset photos show the calcined slag before dissolution.

and $8(\mathrm{~b})$, respectively. The calculation was done by estimation of weight percentages in heat-treated slag by the Rietveld simulation for collecting XRD patterns (Fig. 8(a)). Table 1 lists analyzed weight ratio of compound by the Rietveld simulation. Then, the weight ratio between weight of FAp, bone, and $\mathrm{CaO}-\mathrm{P}_{2} \mathrm{O}_{5}$ (taken 4-20 g) and examined slag (10 g). The addition of compounds such as HAp reagent, pig bone, and $\mathrm{CaO}-\mathrm{P}_{2} \mathrm{O}_{5}$ glass altered the FAp content 


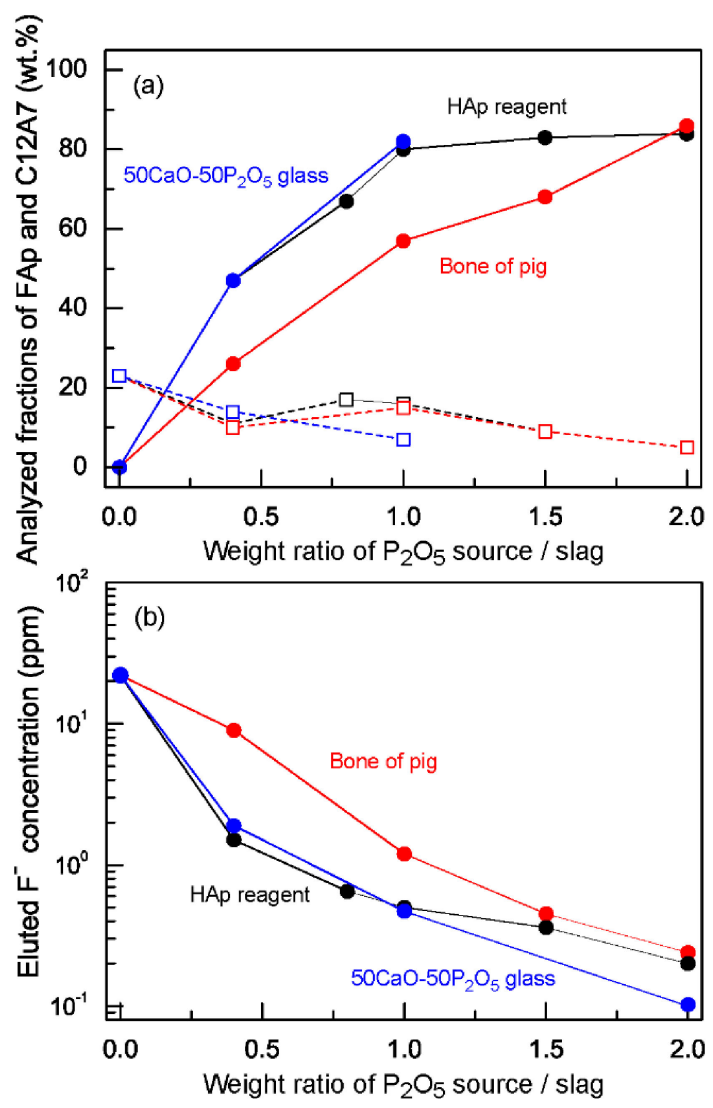

Fig. 8 The calculated fractions of (a) FAp and C12A7 and (b) eluted $\mathrm{F}^{-}$ with a varied $\mathrm{P}_{2} \mathrm{O}_{5}$ to slag weigh ratio. The fractions were calculated of Rietveld analysis method on the obtained XRD patterns of the heat-treated slag mixed with HAp, bone, and calcium phosphate glass.

without increasing the $\mathrm{C} 12 \mathrm{~A} 7$, which remained unchanged or decreased slightly with an increased weight ratio of additive. The more moderate curve caused by the addition of bones was due to the reduced net amount of HAp component in bones when compared with pure HAp reagent or $\mathrm{CaO}-\mathrm{P}_{2} \mathrm{O}_{5}$ glass.

The amount of $\mathrm{F}^{-}$eluted into the water was dependent on both the weight ratio and type of $\mathrm{P}_{2} \mathrm{O}_{5}$ additive, as shown

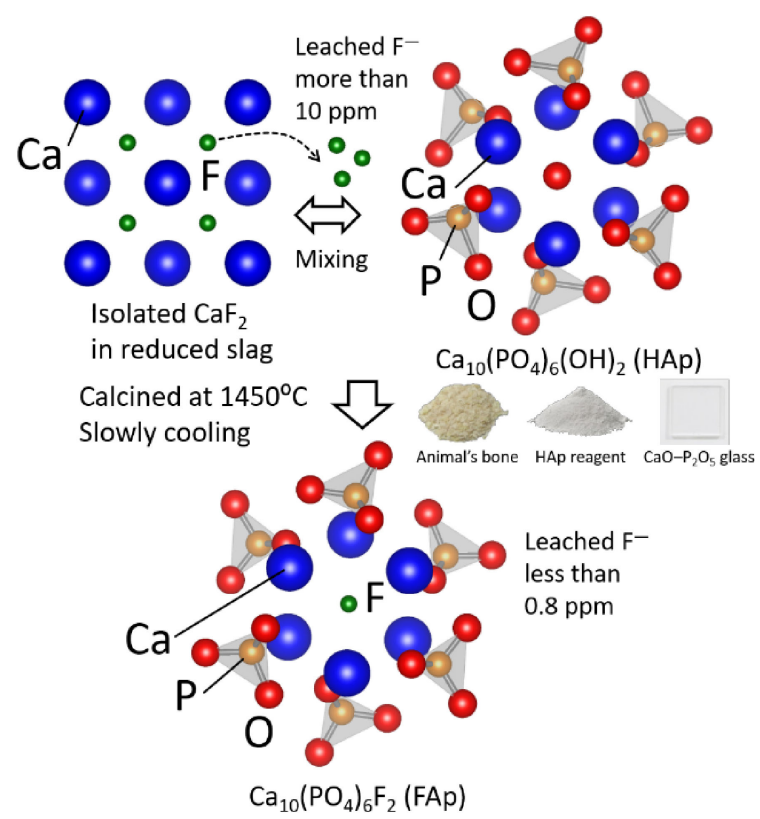

Fig. 9 Schematic of fluorine confinement in HAp crystals allowing for the alternation of stable fluoro-apatite (FAp) crystal.

in Fig. 8(b). When FAp is formed by calcination mentioned above, fluorine ions originating from those in the isolated $\mathrm{CaF}_{2}$ are confined in the $2 \mathrm{a}$ site in the FAp. ${ }^{11)}$ As a result, less than $0.8 \mathrm{ppm}$ of $\mathrm{F}^{-}$was eluted to the water at HAp additiveto-slag weight ratios of 1.0-1.5.

The scheme of movement of $\mathrm{F}^{-}$from $\mathrm{CaF}_{2}$ to FAp during the calcining process, via adding HAp, is shown in Fig. 9. Overall, including $\mathrm{CaO}-\mathrm{P}_{2} \mathrm{O}_{5}$ compounds not dependent on crystalline and glassy substances nor regent or recycled HAp was demonstrated to be suppress the elution of $\mathrm{F}^{-}$from slag. While when no material is added to stabilize fluorine in the reduced slag, eluted $\mathrm{F}^{-}$are quantified more than $10 \mathrm{ppm}$ as shown in Fig. 8(b). Furthermore, the use of recycled, dried animal bones as a source of calcium phosphate in the absence of wet process. ${ }^{7)}$ Application of drying processes with unused and natural resources enables fluorine confinement in the stable FAp crystals.

Table 1 Analyzed weight percentage of compound in calcined sample for variable $\mathrm{P}_{2} \mathrm{O}_{5}$ sources (denoting mixed materials) with different mixing ratios in weight. The observed values are denoted in wt.\%.

\begin{tabular}{|c|c|c|c|c|c|c|c|}
\hline $\begin{array}{l}\text { Mixed } \\
\text { material }\end{array}$ & $\begin{array}{c}\text { Weight } \\
\text { ratio }\end{array}$ & 0 & 0.4 & 0.8 & 1.0 & 1.5 & 2.0 \\
\hline \multirow{3}{*}{ HAp } & FAp & 0 & 47 & 67 & 80 & 83 & 84 \\
\hline & C12A7 & 23 & 11 & 17 & 16 & 9 & 5 \\
\hline & Others & 77 & 42 & 16 & 4 & 8 & 11 \\
\hline \multirow{3}{*}{ Pig bone } & FAp & 0 & 26 & - & 57 & 68 & 86 \\
\hline & C12A7 & 23 & 10 & - & 15 & 9 & 5 \\
\hline & Others & 77 & 64 & - & 28 & 23 & 9 \\
\hline \multirow{3}{*}{$\begin{array}{c}50 \mathrm{CaO}- \\
50 \mathrm{P}_{2} \mathrm{O}_{5} \\
\text { glass }\end{array}$} & FAp & 0 & 47 & - & 82 & - & - \\
\hline & C12A7 & 23 & 14 & - & 7 & - & - \\
\hline & Others & 77 & 39 & - & 11 & - & - \\
\hline
\end{tabular}




\section{Conclusion}

Quantitative structural information is presented for the immobilization of $\mathrm{F}^{-}$from $\mathrm{CaF}_{2}$ to $\mathrm{FAp}$. The addition of HAp (via bone or reagent) or meta Ca-phosphate glasses was demonstrated to facilitate the formation of stable FAp, which resulted in the confinement of $\mathrm{F}^{-}$in the FAp. Powder XRD data and a subsequent Rietveld analysis provided qualitative and quantitative information about the dry conversion process of powdered bones to FAp using isothermal heat treatments. The use of dry processes with unused and natural resources, such as bones, enables calcium phosphate to be obtained sustainably, without depending on the limited and declining resources of phosphorus ores.

\section{Acknowledgments}

The authors would like to thank Prof. Dr. H. Aono (Ehime University) for granting them access to the ion chromatography apparatus.

\section{REFERENCES}

1) J.H. Park, D.J. Min and H.S. Song: Metall. Mater. Trans. B 33 (2002) 723-729.

2) S. Sukenaga, N. Saito, K. Kawakami and K. Nakashima: ISIJ Int. 46 (2006) 352-358.

3) T. Hiraki, J. Kobayashi, S. Urushibata, K. Matsubae and T. Nagasaka: Metall. Mater. Trans. B 43 (2012) 703-709.

4) Soil Contamination Countermeasures Act, 2002.

5) A product having a fear of elution is subjected to the test based on Notification No. 46 of the Environment Agency in 1991 (environmental standards relating to contamination of soil), 1991.

6) L. Veselinovic, L. Karanovic, Z. Stojanovic, I. Bracko, S. Markovic, N. Ignjatovic and D. Uskokovic: J. Appl. Cryst. 43 (2010) 320-327.

7) A. Saitoh, Y. Ishibashi, R. Kihara, T. Sakamoto, R. Hayashi, T. Asahi and H. Takebe: J. Ceram. Soc. Jpn. 127 (2019) 131-135.

8) F. Izumi and T. Ikeda: Mater. Sci. Forum 321-324 (2000) 198-205.

9) W.T. Lankford, Jr., N.L. Samways, R.F. Craven and H.E. McGannon: The Making, Shaping and Treating of Steel, (Association of Iron and Steel Engineers, Pittsburg, Pennsylvania, 1985) p. 421.

10) T. Ishii, A. Mizukami and S. Nagashima: Process of suppressing elution of fluorine in steel-making slag, Japan, 2002.

11) M.E. Fleet and Y. Pan: Am. Mineral. 82 (1997) 870-877. 